\title{
Os egressos como atores do processo de avaliação curricular do curso de Enfermagem da Famema
}

\author{
Undergraduates as players in the curriculum evaluation process of the nursing course at FAMEMA
}

Objetiva-se avaliar o processo de formação do Curso de Enfermagem da FAMEMA, com base na ótica dos egressos formados na primeira turma da mudança curricular. Para tal, decidiuse: conhecer como foi sua trajetória estudantil; identificar sua inserção no mundo do trabalho; conhecer seus conflitos e dilemas, e avaliar as eventuais marcas deixadas pelo processo de formação nas formas de inserção profissional. Analisou-se o caminho percorrido trazendo, como referencial, os pressupostos da avaliação emancipatória, no sentido de tornar visíveis os avanços e vulnerabilidades de um projeto de formação crítico-reflexivo em saúde. A pesquisa foi realizada com egressos, após três anos de formados, e utilizada a técnica de entrevista semi-estruturada para a coleta dos dados. Com os dados empíricos, desenvolveu-se a análise de conteúdo na modalidade temática, identificando, como tema central, as contradições do processo de construção do enfermeiro crítico e, como subtemáticas, os conflitos de ser estudante da FAMEMA e os dilemas da inserção no mundo do trabalho. Os olhares dos egressos evidenciaram que a formação possibilitou construir valores necessários à prática profissional diferenciada, tais como a disposição do aprender a aprender, considerando que a prática é dinâmica e passível de muitas contradições. Possibilitou, ainda, identificar que a proposta de mudança é um projeto contra-hegemônico, necessitando transformações não só no processo de formação, mas na forma de enfrentar os conflitos do mundo do trabalho, que ainda se mantém refém de um modelo de saúde fragmentado.

\section{Silvia Franco da Rocha Tonhom} Tese (Doutorado), 2006 Programa de Pós-Graduação da Faculdade de Educação, Universidade Estadual de Campinas tonhom@terra.com.br

Palavras-chave: Avaliação. Formação crítico-reflexiva. Enfermagem. Egressos. Ensino superior.

Key words: Evaluation. Critical-reflexive education. Nursing. Egressed students. Higher education.

Palabras clave: Evaluación. Educación critico-reflejiva. Enfermería. Graduados. Enseñanza superior.

Texto integral disponível em:

$<$ http://libdigi.unicamp.br/document/?code =vtls 000404174> 